\title{
Importance of field data for understanding a potential Mousterian funerary deposit : the case of the Regourdou 1 skeleton (Montignac-sur-Vézère, Dordogne, France)
}

Bruno Maureille, Trenton Holliday, Aurélien Royer, Maxime Pelletier, Stéphane Madelaine, François Lacrampe-Cuyaubère, Xavier Muth, Erwan Le Gueut, Christine Couture-Veschambre, Asier Gómez-Olivencia, Emmanuel Discamps, Jean-Pierre Texier, Alain Turq and Christelle Lahaye

\section{(2) OpenEdition}

\section{Journals}

Electronic version

URL: http://journals.openedition.org/paleo/3678

DOI: $10.4000 /$ paleo.3678

ISSN: $2101-0420$

Publisher

SAMRA

\section{Printed version}

Date of publication: 1 December 2015

Number of pages: 139-159

ISSN: 1145-3370

\section{Electronic reference}

Bruno Maureille, Trenton Holliday, Aurélien Royer, Maxime Pelletier, Stéphane Madelaine, François Lacrampe-Cuyaubère, Xavier Muth, Erwan Le Gueut, Christine Couture-Veschambre, Asier GómezOlivencia, Emmanuel Discamps, Jean-Pierre Texier, Alain Turq and Christelle Lahaye, « Importance of field data for understanding a potential Mousterian funerary deposit : the case of the Regourdou 1 skeleton (Montignac-sur-Vézère, Dordogne, France) », PALEO [Online], 26 | 2015, Online since 25 June 2018, connection on 07 July 2020. URL : http://journals.openedition.org/paleo/3678 ; DOI : https:// doi.org/10.4000/paleo.3678

This text was automatically generated on 7 July 2020.

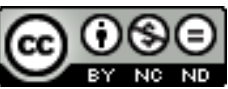

PALEO est mis à disposition selon les termes de la licence Creative Commons Attribution - Pas d'Utilisation Commerciale - Pas de Modification 4.0 International. 


\section{Importance of field data for understanding a potential} Mousterian funerary deposit : the case of the Regourdou 1 skeleton (Montignac-sur-Vézère, Dordogne, France)

Bruno Maureille, Trenton Holliday, Aurélien Royer, Maxime Pelletier,
Stéphane Madelaine, François Lacrampe-Cuyaubère, Xavier Muth, Erwan
Le Gueut, Christine Couture-Veschambre, Asier Gómez-Olivencia,
Emmanuel Discamps, Jean-Pierre Texier, Alain Turq and Christelle Lahaye

We wish to thank the National Museum of Prehistory and its director Jean-Jacques Cleyet-Merle and the Museum of Art and Archaeology of the Périgord and its curator Veronique MerlinAnglade for their authorizations to study the fossil material and the collections kept in their institutions. We express our gratitude to Michèle Constant for the loan of part of the collections of the Regourdou site she keeps in the site museum. We are grateful to E. Bonifay who gave us very numerous archives and unpublished documents on the excavations he directed in Regourdou from 1961 to 1964 as well as on the rescue of 1957. We are thanking him and B. Vandemeersch for our friendly exchanges on the results presented in this manuscript. Finally, we wish to thank M. Lenoir who helped to transcribe the minutes written by François Bordes and G. Devilder for his work on Figure 1. This research was possible thanks to the Transitions project convention 20051403003AB of the Aquitaine region, the project Nemo of the LabEx archaeological Sciences Bordeaux, a program funded by the ANR - $n^{\circ}$ ANR-10-LabX-52 project $A^{*}$ MIDEX No.ANR-11-IDEX-0001-02, managed by the National Agency for research under the Investments for the Future program, the project CGL2012-38434-C03-01 of the Ministerio de Economía $y$ Competitividad (Spain) and the IT834-13 investigative group of the Eusko Jaurlaritza / Gobierno Vasco, the Louisiana Board of Regents LEQSF (2015-18)-RD-A-22. 


\section{Introduction}

1 One of the features of archaeological excavations is the inability to reiterate them and to acquire a second time, with different techniques, new information. The excavation of a Pleistocene site inevitably leads to its disappearance. Archaeologists compensate this specificity by saving the field information in various ways, often through notebooks or excavation diaries, by multiplying photographs and then by using recording methods that place the remains, samples and structures in a system (usually Cartesian). These methods, developed as early as the years 1930-1940 by researchers such as Laplace and Méroc (1954), have probably led in October 1957 the excavators of the Regourdou 1 human remains to record - for the first time for a Mousterian skeleton - information on the position of the remains in relation to stones, to a post and an axis. Despite highly hazardous working conditions and an excavation that was a rescue operation, coordinates in two-dimensional space of several remains were taken in addition to photographs, to two drawings and to field minutes. The information available on the human remains of Regourdou 1 had not been considered until now, questioning us also about the contributions and potential limitations of their use.

2 The purpose of this contribution is to present a first level of understanding of the position of human remains discovered in September-October 1957 based on field minutes written by F. Bordes (who directed this operation), on the two drawings done and some photographic shots. A second level of understanding will be proposed by combining this information with what we can deduce from what is recorded or associated with the human remains (some unearthed during the scheduled excavation led by Eugene Bonifay and see also Gomez-Olivencia et al. 2013; Maureille et al in press). All of these sources will allow addressing some of the taphonomic history of the Regourdou 1 skeleton during the Mousterian, then to re-evaluate the position of the human remains within the site and to question ourselves on the body position of this Neanderthal. 
Figure 1 - Location of the Regourdou site.

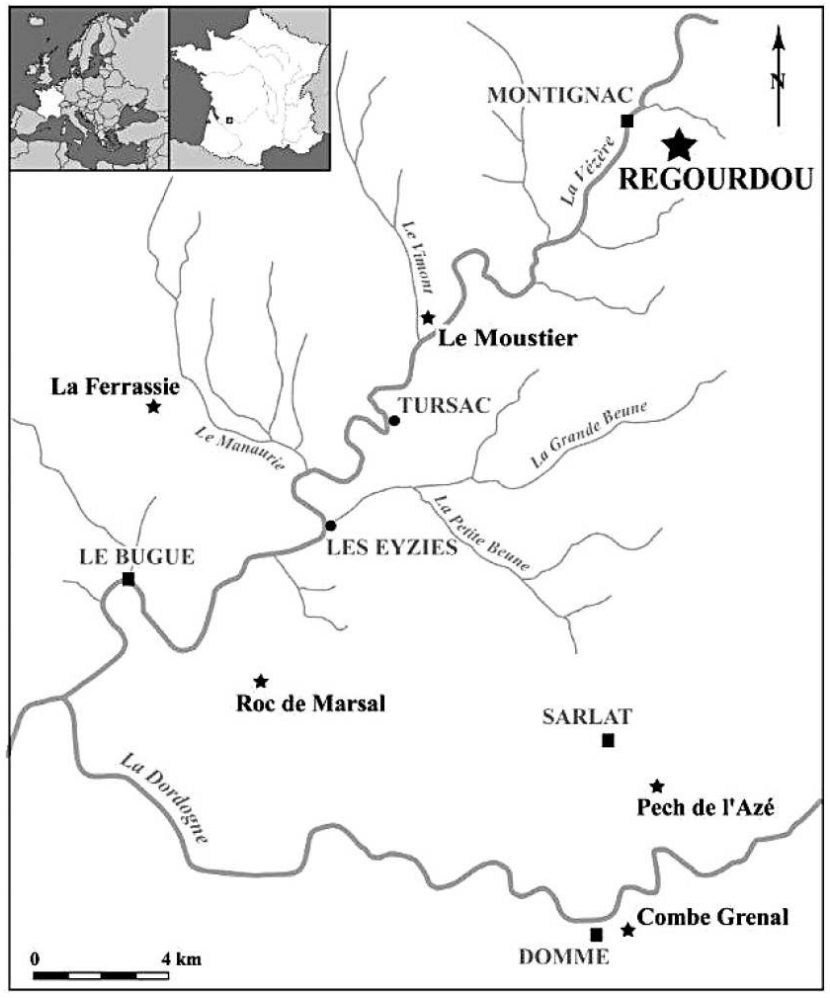

Figure 2 - G. Laplace-Jaurechte working before the shoring up of the gallery dug by R. Constant. Picture F. Bordes collection, SRA Aquitaine.

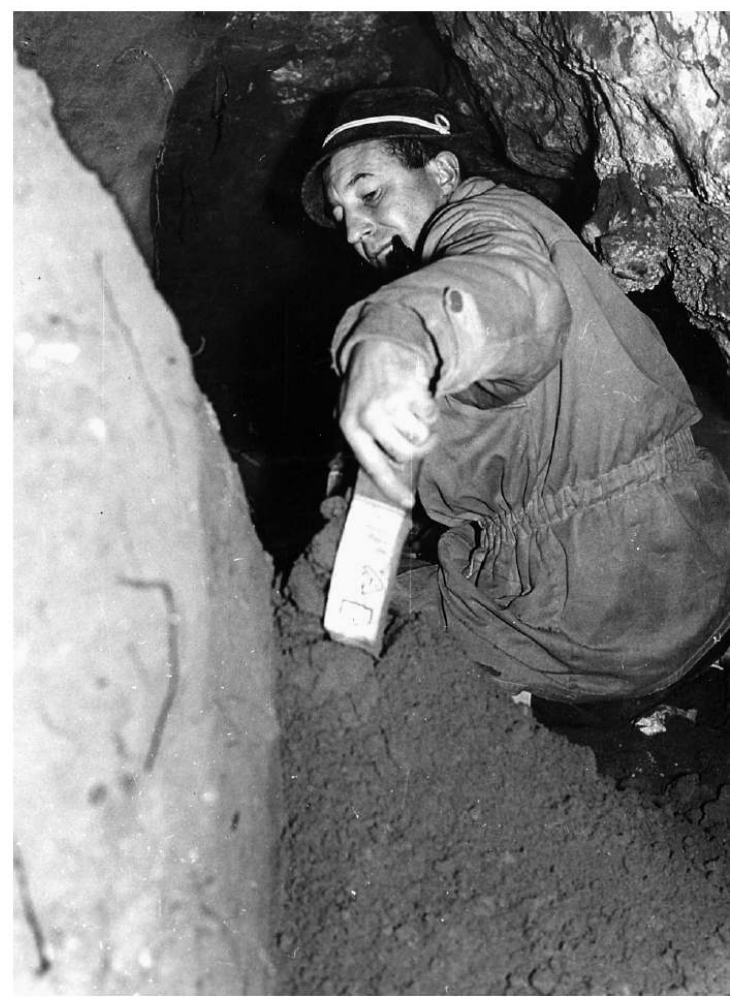




\section{1 - Regourdou and the data provided by the field minutes written by François Bordes}

3 The site is located at a place called "Regourdou north" by the town of Montignac-surVézère (Dordogne, France ; fig. 1), on the left bank of the Vézère valley, at the top of the hill that also houses the Lascaux cave and the prehistoric complex of La Balutie (Reverdit 1879; Delage 1939).

4 In 1955, its owner, R. Constant, demolished stables, dug the ground in front of his house and penetrated into an old collapsed cave. He then followed the western wall by digging a narrow tunnel in the sedimentary filling that quickly yielded archaeological artefacts. In the night of September 22 to 23, 1957, and in destructive circumstances, the human remains of Regourdou 1 were discovered (Piveteau 1959; Bonifay 1964). Their excavation was initiated only at the beginning of October after consolidating the entrance to the tunnel dug in the filling and building a hard structure above this access. After numerous delays, a rescue operation began on October 2 in difficult conditions. It was carried out by E. Bonifay and G. Laplace-Jauretche (fig. 2) under the administrative authority of F. Bordes. The latter began by unearthing a flint and a phalange, perhaps human, in front of the mandible. But quickly, F. Bordes decided to stop the work because of collapses that threatened the safety of the excavators and the integrity of the human remains. A timbering was set up in the gallery (fig. 3). This was done on Tuesday, October 3 and early morning on October 4, 1957. After removing the protection above the bones, that same day, F. Bordes and R. Constant, found the remains in the same state they were the day before. By then, the identified human remains were a hemi-mandible, half-unearthed, a vertebra and two broken long bones, the missing part of one of them being in a niche dug into the fine sediments of the filling before the discovery in September (fig. 4). The excavation continued and ended on Friday 4 and Saturday 5, October 1957 (fig. 5).

We are reproducing below the field minutes of these two days recorded by F. Bordes, a copy of which is kept in the archives of the Museum of Art and Archaeology of the Périgord (MAAP) and two drawings associated with them ( fig. 6 and 7). The original notebook of these minutes and the two drawings were entrusted to E. Bonifay by $F$. Bordes on April 8, 1961 (Bonifay 1961 unpublished). The transcript (below) of these minutes is integral (but without following the line returns of the format of the notebook used). However, F. Bordes' writing is hard to read and we could have wrongly transcribed some words. We have added to F. Bordes' text the passages in bold and that are not italicized. They correspond to explanations we consider useful to the understanding of these minutes and of the drawings.

\section{$V / 9 / 1957$}

$10: 40$ to $11: 20$ - after the end of the timbering, clearing of the collapse - the planks and the hardboard plate set as protection before the collapse were removed - the human remains have not suffered thanks to the protective measures.

Signature François Bordes

Signature Roger Constant

Bonifay $10: 45$ - beginning of the clearing work-

1 hearth, probably the upper one, passes over the stone partially covering the mandible or inside of on the surface of the hearth passing over the stone (on about $1 \mathrm{~cm}$ thick) Ursus 
tooth

Provisional stratigraphy in burial area, slightly forward

1. collapsed blocks

2. layer of reddish earth sand with concretions fragments and numerous flint, Helicelle and Cyclostoma (elegans?)

3. line of stalagmitic concretions, thicker toward the back

4. stratified red sand with light passes at the top and greyish at the base

5. grey sand

6. hearth

7. grey or reddish sand. - Skeleton thereby

8. 2nd hearth less clear than the former, reddish sand with grey traces and numerous charcoals - Skeleton thereby

Between both hearths, $60 \mathrm{~cm}$ in front of the skeleton, entrance of burrows (rabbit?) penetrating the red layer between both hearths and filled by the upper hearth

$11: 15$ - red sand penetrates between stones - likely burrows -

$11: 30$ - long bones appear, one directly with fresh fracture, showing from the area in place 4 small fragments collected. The long bones are most likely the right humerus that appears at the level of its proximal third or mid-length of the diaphysis (No. 18, figure 6) and the distal half of the right radius (No. 19, figure 6). The fragments were not numbered.

12.30 - 6 colour photos - burial

$14: 45$ - stones and a vertebra removed (No. 13). This bone is kept in the Regourdou site museum. Identified "Reg. $1957 \mathrm{sep} \mathrm{13,"} \mathrm{it} \mathrm{is} \mathrm{a} \mathrm{complete} \mathrm{bear} \mathrm{thoracic} \mathrm{vertebra} \mathrm{(No.} \mathrm{13,} \mathrm{figure}$ 6, this vertebra is also visible on figure 5 in front and on the left of the brush).

under small stones, under stone 4 indeterminable bones, crushed, pressed against the lower side

Atlas removed - There was no human atlas among the bones acquired by the Museum of Art and Archaeology of the Périgord. This may be a bear atlas (but there are none in the window of the burial in the Regourdou site museum).

Clavicle fragment (?), broken prior to the excavation This is probably the thoracic extremity of the right clavicle. It is not shown on figure 6 but was located between objects 18 and 19.

The two long bones projecting from/under block 2 are broken / the extremity was in the "niche Constant" -. We believe that the proximal part of the right humerus was part of this material.

Long bone under flint 3 broken in place

old fracture - recently broken extremity - side Constant excavation - 4 fragments collected. They do not seem to have been numbered.

Red earth in contact with long bone -

Possibility recent disturbance

Laplace

$15: 15$ - stone $n^{\circ} 5$ in 3 pieces at the level of flint 16, placed under stone 15, earth +reddish

$15: 30$ - long bone 18 removed - as well as fragments of the 1/2 mandible- under long bone 18, broken bone with recent break - prior to the excavation of this day continuation of long bone 18 in the "niche Constant" under the long bones 18 and 19, several broken bones whose pieces are lacking and looking in remains of the "niche Constant" phalange near jaw. This is perhaps the object in two pieces identified on figure 7 by the No. 29

$15: 40$ - long bone 19 (1 half) only

1 ungual phalange behind the mandible a broken rabbit jaw

$15: 50$ - it does seem that the majority of these objects has been removed and replaced more or less in place by the excavators

$16: 00$ - block $n^{\circ} 2$ removed, below continuation of the mandible and numerous bones colour photos taken -

crushed long bones under flint 3, placed on slab covering the skeleton and covering other stones / flint tooth $\left(n^{\circ} 3\right)$ 
$18: 00$ - removal of the second part of the mandible after varied bones - numbered on plan-it was stuck between two stones. A stone under the mandible - marked X-other bones taken out

$19: 00$ - end of work-

1 human tooth found by Ch. Delfaut in charge of sieving the previous excavation wastes

\section{Saturday, October 5, 1957}

$9: 20$ - continuation of the excavation by E. Bonifay. The upper hearth seems to pass on top of the burial

a portion of the bone appears in the lower hearth (some phalanges removed by Constant during discovery) flint no. 45 by 30 axis and 4 post, in lower hearth at the level of the bones

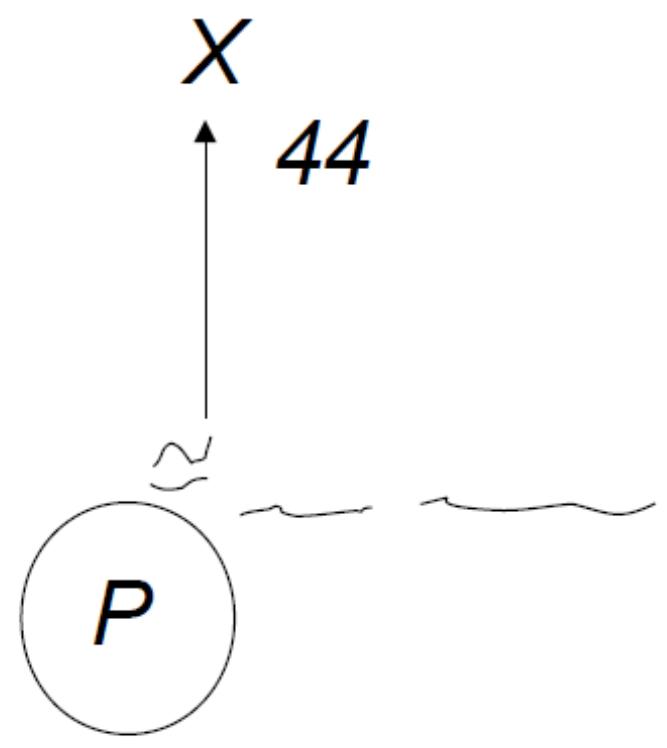

1 retouched flint (46) - just below the large bone (bovine?) at 44 axis and 2 from the post $10: 10$ - bone 49 with old fracture - removed bone $47: 3$ or 4 pieces - among which 1 vertebra under bone 47 probably sacrum

3 bone group

$\underline{50}$ on $49-\underline{51}$ : under large long bone $44+$ or - No. 51 is assigned to at least 3 elements of fauna : a claw, a distal epiphysis of an immature bear tibia, a vertebra of small mammal. We still have not identified this large long bone numbered 44. $11: 10$ - having to remove the bones from underneath - collapse level- the hearth passes over the burial, which appears between the 2 hearths-

$11: 20$ - 52 removed - (group)

48 removed in part -

decided to deepen the excavation from 0 to 10

$11: 45$ - large stone No. 53 removed - in / hearth sup No. / upper reference

Laplace

Flint no. 54 below [or above, we are not sure to read this part of the text correctly] and

at the back of bone 48 (pseudo-Levallois point)

waste under stone 53- fragments in the layer - group 55 : 90 axis- 30 post 
$14: 30$ - Bonifay

bone with cotyloid cavity; burnt in the hearth above the burial - behind post, $21 \mathrm{~cm}$ away and - 10 - (56). Bone No. 56 corresponds to a fragment of bear pelvic bone. As it stands, it does not show signs of burning and the black color could be related to manganese deposits. Continuation of 48 - comes in pieces.

$15: 00$ - part of a pelvis? In fragments- very fragile, falls into pieces- we would need to be able to take it from the top which is impossible as very heavy work needed

patella? and metatarsal bone 80 axis -12 post

1 bones tarsus? foot-

$15: 30$ - stopping the excavation in this direction, we are looking on the right for evidence of skull

flint (58) 60 from post and -20 axis

1 jaw (59) for 78- 15 axis - This is a fragment of deer hemi-mandible.

in red earth with charcoals, under the hearth-

about the level of flint 58

flint No. $60-100$ and -10 axis

idem

bear tooth (No. 61) 85 and +12 axis [an horizontal arrow above 85 and a vertical

above +]

tooth Homo ( ?) in hearth - 55 and 40 axis

No. 62

map/me, toward 70 axis - crushed jaw of Ursus and one phalange (Homo?) No. 63, in old burrow +1 bone

auto "carpus" In the collections of the site museum, an object marked

"Regourdou sep $1957 \mathrm{n}^{\circ} 63^{\prime}$ is a bear canine.

1720 - completion of works

To be noted the absence of the skull, the face, except perhaps a few isolated incisors

Signature François Bordes

During the rescue operation, the recording of the stones, flints, bones (human or faunal) was mostly achieved through the two drawings in pencil (a majority of the object numbers is written in ballpoint pen). The coordinates $(0, \mathrm{x})$ and $(0, \mathrm{y})$ of some objects are noted in the field minutes. Unfortunately, these two drawings do not have the same origin point nor the same scale. Drawing No. 1 is done approximately to the $1 / 10$ scale. Drawing No. 2 seems, from the written scale, to have been done at the scale $1 / 2.5$. We believe they represent three episodes of the excavation :

- the first one (fig. 6) shows recorded stones (No. 1 to 12) and archaeological objects (No. 13 to 19)

- the second drawing (fig. 7) illustrates the second episode that follows the removal of the limestone block No. 2 indicated on drawing 1. The objects No. 21 to 42 are represented. A long bone of large dimensions (fauna?) is numbered 44. It was located against and under the block No. 2. No object numbered in this drawing is coordinated in the minutes;

- finally, the third episode is transcribed on drawing No. 1 (fig. 6). It corresponds to objects No. 43 and 47 to 56 and to the stone No. 53. But all the objects have not been represented, perhaps to avoid overloading the drawing, because it was more convenient or to save time (the rescue excavation lasted between 12 and 13 hours). The last objects, for some numbered, were therefore only coordinated in the minutes and are not drawn: No. 60 (a flint), 61 (a bear tooth), 62 (a supposedly human tooth) and 63 (a potentially human phalange plus a carpal bone).

7 Among all the recorded objects, the human remains are rarely identified as such while some other remains are determined as bear or deer. Moreover, many objects recovered during these two days are not coordinated in the minutes or on the drawings or even 
listed. Just for the material presented in a window display in the Regourdou site museum and associated with the casts of the Regourdou 1 bones, 26 objects can be counted as coming from the area where those were found out of which 10 (vertebrae, patella, phalange, canines, proximal extremity of bear radius and a bear cub tibia) can no longer be located due to imprecise marking such as "Reg. 1957 sepult. ou Reg 1957 sep. vrac." Fifteen other remains (vertebra, shaft fragment, coxal bone, femur, radius and tibia of immature bears, vertebra of small fauna and a piece of antler) are also present in this window display and are not marked at all. It is therefore not possible to confirm whether they were unearthed during the rescue operation even if this seems the most likely hypothesis.

Figure 3 - View of the distal part of the north-south gallery dug by R. Constant.

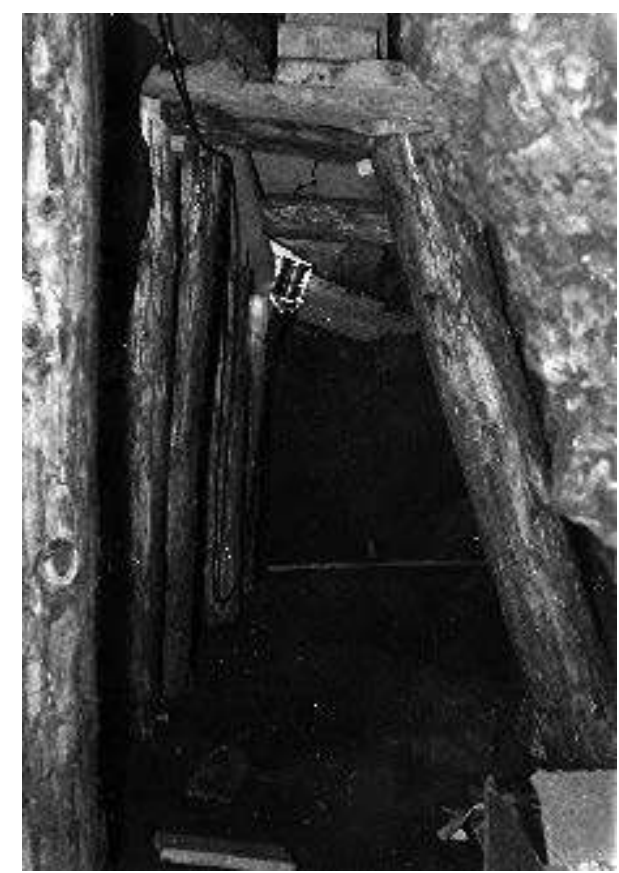

One can make out in the background an unfolded meter stick and the end of a brush. They are resting on a block under which the human remains were found. Picture F. Bordes collection of the SRA Aquitaine. 
Figure 4 - View of the gallery dug by R. Constant after its shoring up.

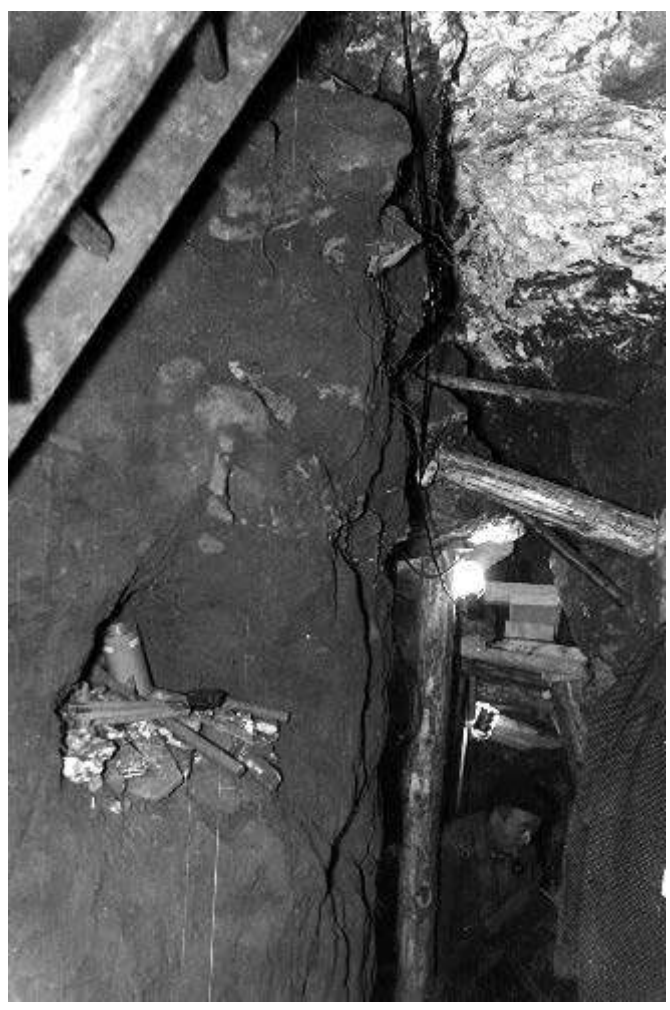

Note the niche dug out on the left. M. Sarradet is to the right with R. Constant in the background. One can also make out F. Bordes' back. Picture F. Bordes collection of the SRA Aquitaine.

Figure 5 - View of the human remains during the course of their removal.

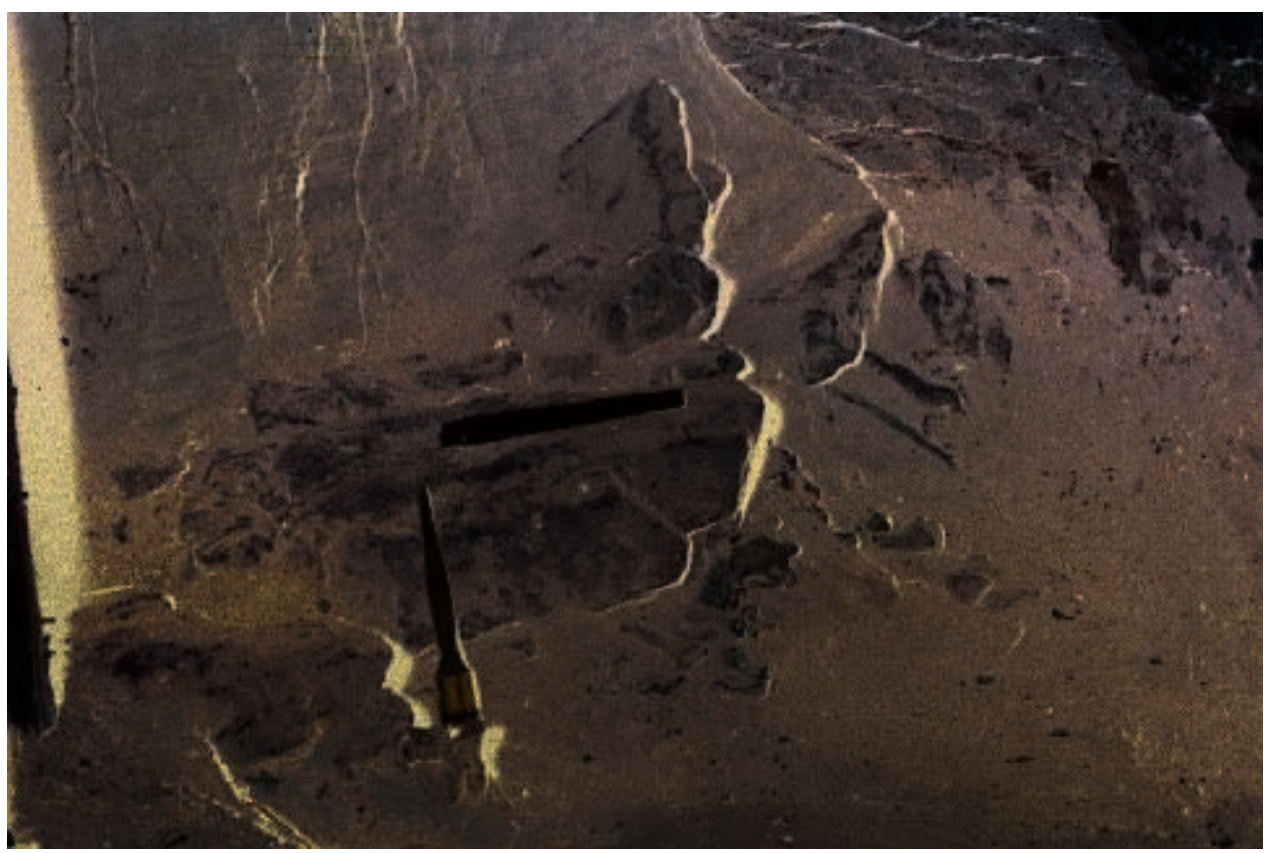

One notes again the meter stick and brush that were visible in figure 4, albeit in different positions. The mandible, a cervical or thoracic vertebra, the diaphysis of a freshly broken long bone, and the distal end of a right radius are all easily recognized. Photo E. Bonifay, F. Bordes collection of the SRA Aquitaine. 


\section{2 - New information}

\section{1 - Re-evaluation of the rescue-related data}

8 remains. However, drawing 2 presents a different point of origin $(0,0)$ and scale from drawing 1 . Moreover, the latter is wrong because, for example, the length of the ulna (remain No. 20) - which is most likely represented whole and in sub-horizontal position as shown in figure 8 - would be about $110 \mathrm{~mm}$ long against $225 \mathrm{~mm}$ for the original object. On this figure, it is also possible to observe a wooden measuring tool that could be parallel to one of the reference axes. Thus five centimetres on the drawing would represent $20 \mathrm{~cm}$ in the excavation, the scale of this drawing $\mathrm{n}^{\circ} 2$ would be of $1 / 4$. The latter thus allows to obtain an acceptable length for the ulna or for the height of the body of the mandible. We then superimposed the two drawings (fig. 9) by putting them at the same scale and considering that :

1. the bone $\mathrm{n}^{\circ} 44$ is against the block $\mathrm{n}^{\circ} 2$ (as recorded in the minutes);

2. the pieces 31 and 32 of the left hemi-mandible are located under the fragment of the right hemi-mandible;

3. the humerus fragment 26 is roughly in line with No. 18 ;

4. the fragments of radius 19 (drawing 1, fig. 6) and 24 (drawing 2, fig. 7) are also in line with one another.

Thus it appears clearly that the majority of the bones collected in 1957 are located below the stone 2 .

The minutes written by F. Bordes give little information on the anatomical identification of the bones collected. No listing was found inventorying more or less precisely all the collected archaeological objects (we assume it must have existed) and the object numbers. However, the combination of all the photos and drawings allows us to re-allocate some of these numbers to some anatomically determined human remains (Annex). Thus, the right hemi-mandible is not numbered, not on the minutes nor on the drawings, but it is located near the numbers 15, 16, 18 and 19. As the number 17 is not given, we are suggesting that this number corresponds to the two fragments of this hemi-mandible. It is also possible to match the numbers 31 and 32 to the mandible (its left part), 19 and 24 to the right radius, 20 to the right ulna. The number 27 can be attributed to two metacarpals (fig. 7 and 8) rather than to phalanges as is written on the drawing and the minutes. In addition, some bones have not been numbered, but their marking gives information on their localization thus allowing to reposition them on the drawings. For example on the $2^{\text {nd }}$ left metacarpal, the following is written "Reg Sep 1957 sur le bloc où était la p. droite de la Md" (Reg Sep 1957 on the block where was the right p. of the Md). On the two distal third of the right fibula, it is written "Reg 1957 sepult. sous pierre $n^{\circ} 1^{\prime \prime}$ (Reg 1957 burial under stone No.1). To these examples, other cases can also be added like the marking on the right clavicle "Reg. 1957 sépult." This does not allow to position it, but we can determine its location through photographs taken during the rescue excavation (drawing 1, fig. 5). Indeed, its lateral extremity is seen by its dorsal face between the right humerus and radius. Finally, on figure 5 , the left ulna is seen by its posterolateral face. On drawing 2 , the object is numbered " 42 ". It is marked "Reg. sep. 1957 Reg 4 ". We can suppose that the 2 is now faded. But we are 
not sure whether this is the same object as the one noted " côte" ("rib") on drawing 1 (fig. 6) that appears to us to be located exactly at the same place.

11 The identification of the bones (human or faunal), of the associated archaeological material, the inventory of their marking, the study of the minutes, the photos and the two drawings allows us to offer a kind of "synthetic statement" with all the information we have been able to compile (fig. 9 top and 9 bottom). It shows that a third of the human remains unearthed on October 4 and 5, 1957 are distributed under the stone $\mathrm{n}^{\circ} 2$ (fig. 9). This is essentially the upper part of the individual, with the jaw, the shoulder girdle, the trunk and the upper limbs (fig. 9). The faunal and lithic remains are, in turn, mainly located around this stone and especially to its left and back (or toward the south-east) near the human bones (ribs, lumbar vertebrae, coxal) of the lower body. The tuberosity of the ischium of the right coxal (No. 47) and the nearby sacrum (drawing 1, fig. 6) of Regourdou 1 were also unearthed in this area. Two other pieces of human coxal (Annex) have been identified under the "femur? " (fauna?) shown on drawing No. 1 . The right fibula, marked "Reg 1957 sepult. sous pierre $n^{\circ} 1$ (Reg 1957 burial under stone No.1)" is located slightly ahead of this zone (fig. 9 top and bottom) and the stone No. 2, between the vertebra No.13 and the coxal No. 56, both of Brown Bear, described in the minutes as burnt (see above).

If all this seems to indicate random positions of the human remains, we are noting despite everything - the respect of the anatomical logic of the body segments of an individual with, for example, the proximity of the mandible and the cervical vertebrae, of the distal extremities of the right humerus and proximal ones of the right radius and ulna or again the elements of the upper limbs and of the trunk between the mandible and pelvic girdle bones. However, no anatomical connection could be found, except for two likely metacarpals stuck against each other (fig. 8). They appear seen by the same extremity and located between the distal end of the right ulna and a third metacarpal (second right?). 
Figure 6 - A : Original drawing $\mathrm{n}^{\circ} 1$ done in October 1957 ; $\mathrm{B}$ : An informative retranscription of the same drawing.

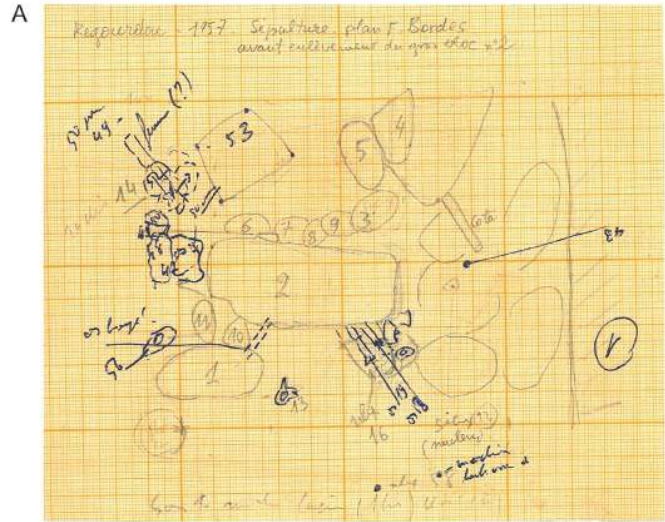

B

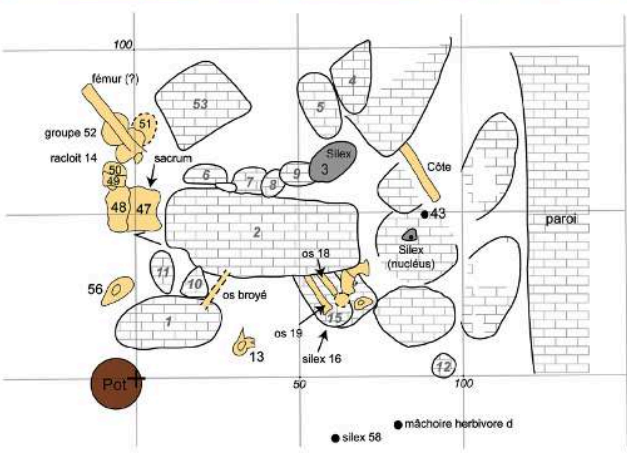

Figure 7 - A : Original drawing ${ }^{\circ} 2$ done in October 1957 ; B : An informative retranscription of the same drawing.
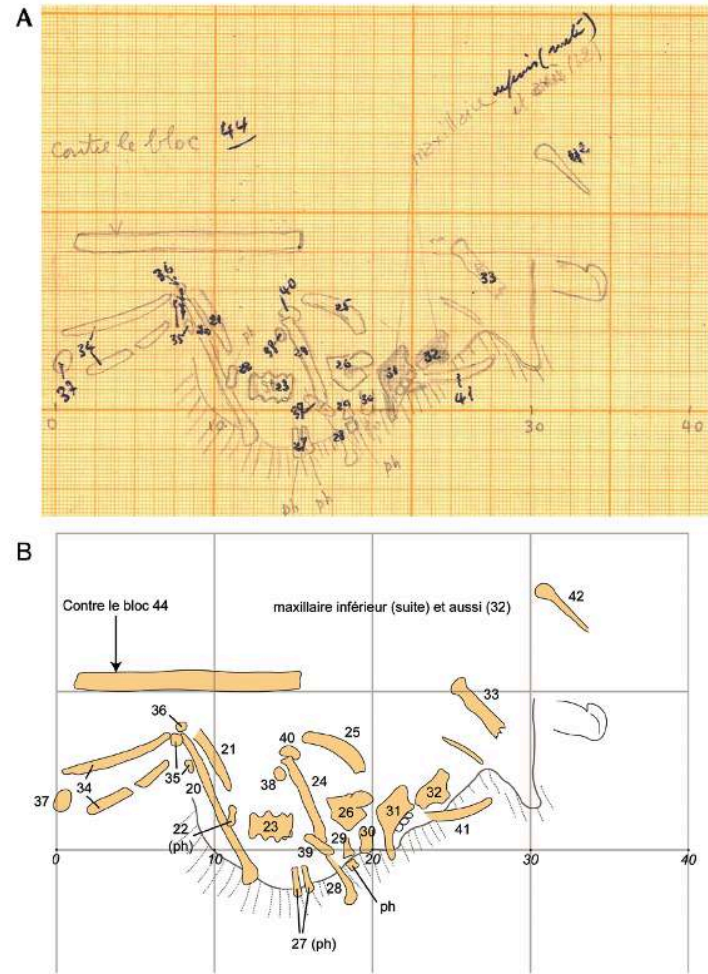
Figure 8 - View of the human remains during the course of their removal after the removal of block no. 2 visible in figure 6 and the removal of a number of human osseous remains.

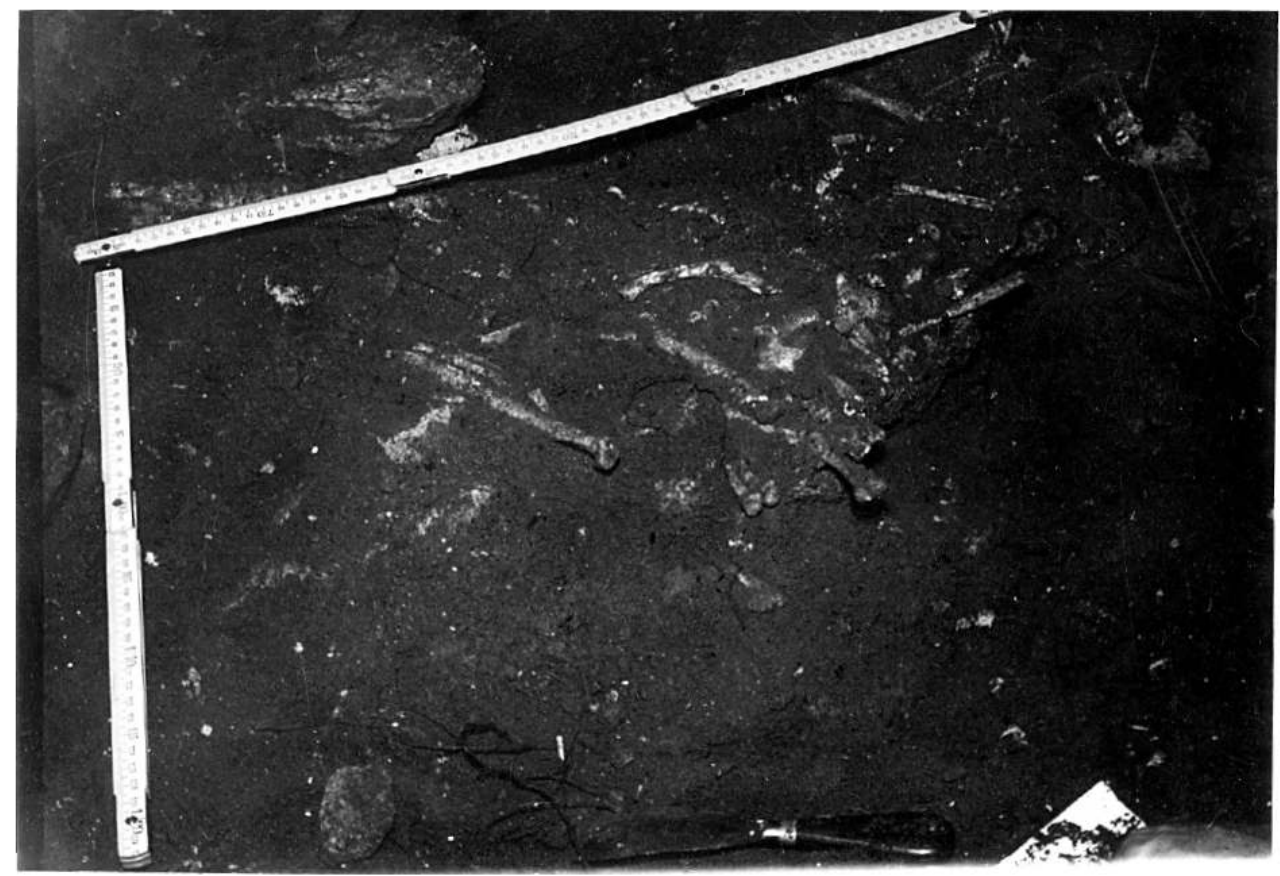

On the upper left one easily recognizes the right ulna with its distal end clearly visible. In the foreground one notes the presence of three metacarpals. Photo E. Bonifay, F. Bordes collection of the SRA Aquitaine.

\section{2 - The location of this concentration of human remains}

During or after the 1961-1964 excavations, it is possible the human remains collected during the rescue operation in October 1957 have been repositioned in the grid established at the time but we have not found any trace of this work. Only the figures of Bonifay's publications (Bonifay, 1964, 1965 ; Bonifay et al. 2007) position the IVa scree that yielded these human remains (Bonifay and Vandermeersch 1962) on the rows 1 to 2 according to the east-west section and on the rows $\mathrm{G}$ and $\mathrm{F}$ according to the northsouth section. Note that on the published plans (Bonifay et al. 2007) the authors consider that the IVa scree was spreading on the squares G-H and 2-3, its part in the $\mathrm{H}$ row having been removed during the work conducted by R. Constant previously to the discovery.

14 It is possible to specify the location of the concentration of human remains from the photographs, the two drawings done in 1957, the various plans of the 1961-1964 excavations and E. Bonifay's field notebooks (who gave us a typed transcript at the beginning of the scientific project of resuming the excavations at Regourdou). According to these documents, the simplest hypothesis is to consider that the human remains were in square G2 (fig. 10A and 10B). Indeed, the concentration of the human remains was situated at least $40 \mathrm{~cm}$ from the wall (fig. 5), that is to say in one of the two rows ( 1 or 2 ) closest to it (fig. 10A). Besides, we assume that, in fig. 10A, the post to the left of the sitting excavator is the last post that was used to shore up the gallery dug by Constant. It could be the one that has been used as a reference to define the origin of the two axes allowing him to coordinate the objects (see drawing 1, fig. 6). It certainly is 
in square $\mathrm{H} 2$ not far from the boundary between it and square G2. According to figure 6 , the human remains are about $20 \mathrm{~cm}$ further to the south/south west of this post. Moreover, it is interesting to note that Bonifay et al. $(2007$, p. 9) indicated the existence of two bear tibias in line with the Regourdou 1 body, "at the location of the legs (if they had remained laying)." These two tibias, unearthed in 1961, are shown in figure 10B. The proximal extremity of the northernmost is also visible in figure 10A. It is in square G2 at least for the proximal two thirds and for the remaining third in square G3 rather close to the boundary between the $\mathrm{G}$ and $\mathrm{H}$ rows. The second tibia seems entirely into square G3.

Given the position of the wall on the 1957 photos (fig. 5 and 6) and the position of the grid set up by E. Bonifay in 1961, all of these documents allow to suppose, with a small margin of error, that the concentration of human remains excavated in 1957 was located in G2.

Figure 9 - Preliminary attempt at the superposition of the two drawings by Bordes with the osseous pieces discovered in 1957 (in the form of points, above, and below with the outlines of the osseous elements - most are in random orientation) that we were able to reposition using field notes and drawings/photos of the archaeological objects.

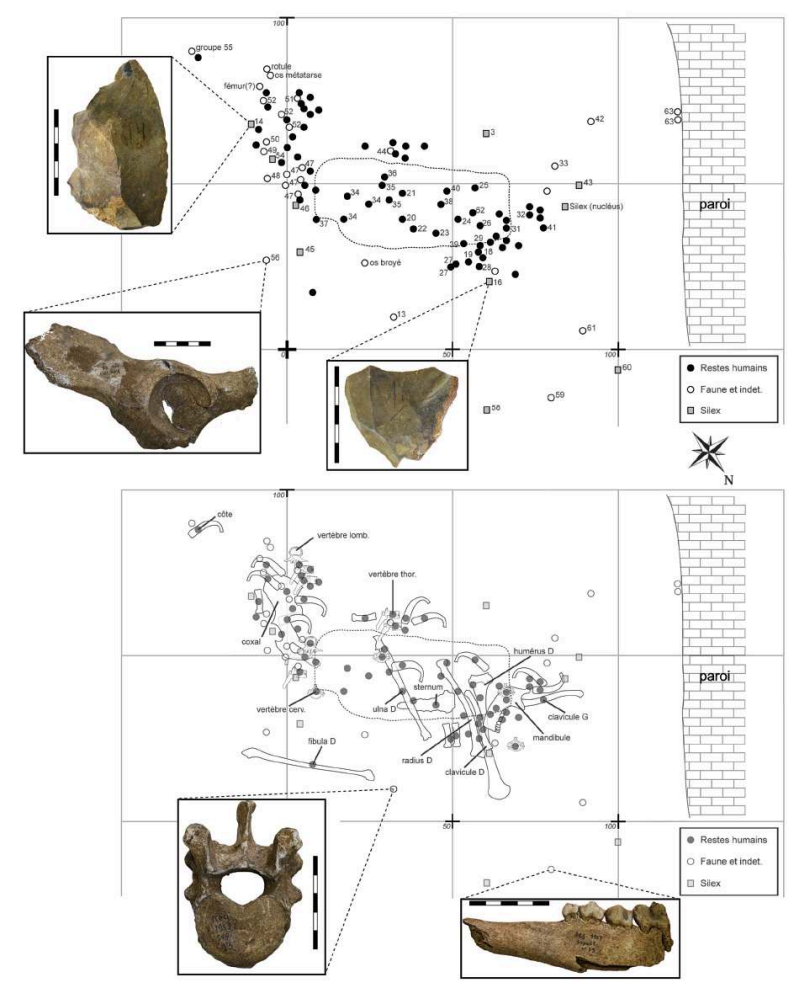


Figure $10-A$ : View of the end of the gallery (with one of the excavators seated) dug by R. Constant after the 1961 excavations and their associated grids were put in place.
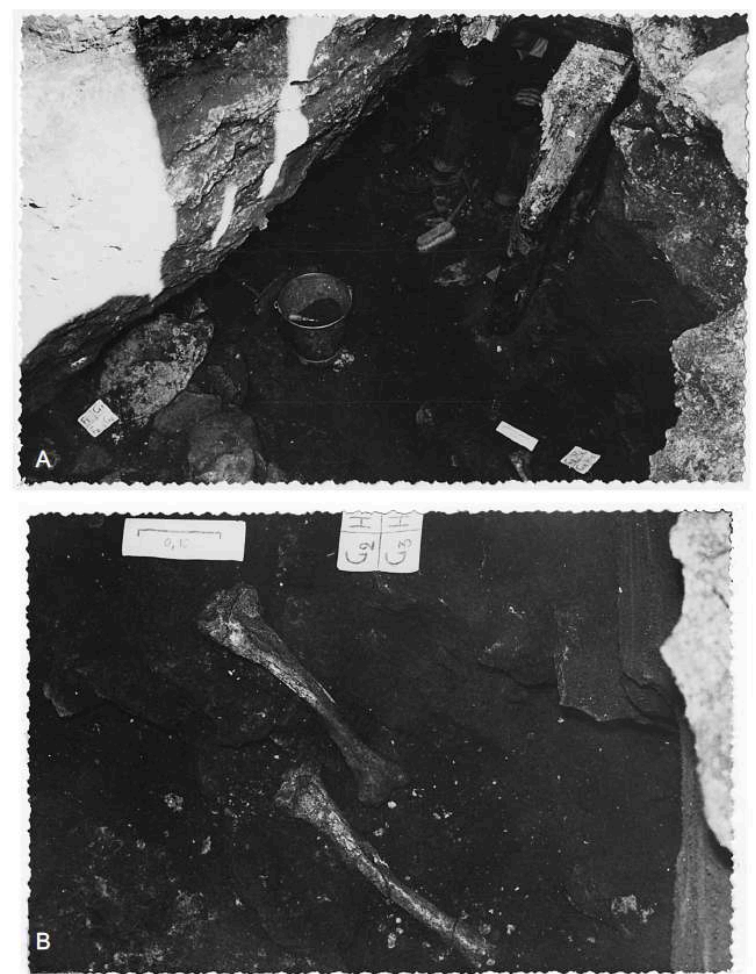

Note, too, the presence of the wooden posts used to shore up the gallery. The last one could be the one represented on the original drawing $n^{\circ} 1$ (fig. 6). In such a case, the area where the human remains have been discovered is in the square G2. Photo E. Bonifay. B : The two brown bear tibiae that came to light in 1961 in the extension of the Regourdou 1 body. The one above is B located in G2, the one below is located in G3. Photo E. Bonifay.

\section{3 - Integration of data from the excavations directed by E. Bonifay}

From 1961 to 1964, E. Bonifay directed two annual excavations campaigns at Regourdou. They have allowed collecting - on the entire stratigraphy of the western half of the site - hundreds of lithic remains and several thousand faunal remains of large and small vertebrates, mainly Brown Bear and many bones of rodents and lagomorphs. These were the subject of various studies (Simard, 1968 ; Donard 1982 ; Bonifay 1989, 2008 ; Delpech 1996 ; Cavanhié 2009-2010 ; Pelletier et al. in press).

Recently, following the acquisition of the collections by the National Museum of Prehistory, new human remains were isolated (Madelaine et al. 2008). Some remains, less numerous, also came from the material still kept by the Constant family at Regourdou (Maureille et al. In press). These remains, coming mostly from the collections of the excavations directed by E. Bonifay, were coordinated, thus providing new spatial directions. Figure 11 shows the position of the concentration of human remains in G2 considering that the post used as reference for the drawings (fig. 6) during the rescue is located in square $\mathrm{H} 2$ and "close" to its SE angle (fig. 10A). The human remains attributed to Regourdou 1 are spread over no less than nine different squares (G1 to G3, F1 to F3, E1, E2 and D2). Their distribution on the plan represents an area of $3.8 \mathrm{~m} 2$. Squares G3, F2, F3 and E2 respectively yielded 12, 5, 4 and 2 remains while the squares D2, E1, F1 and G1 only yielded one. According to the plan provided by 
Bonifay et al. (2007), the human remains would therefore be spread within the IVa scree (the material in G2 and G3), potentially also within the north wall IVa' (F1 to F3), within the IVb scree (E1) and the IVc pit (E2). One human remain unearthed in F3 with the No. 92 would come from layer 7 . The spatial distribution of the human remains does not suggest that it is the result of post-depositional anthropogenic processes during the Mousterian or even related to the discovery of the human deposit at the end of the summer 1957. Indeed, relative to square G2, the remains are all (except two) located further south and to the east, therefore in an area non-affected by R. Constant's work. One bone is situated in G1 (the right calcaneus) and another in E1 (a proximal phalange of the right foot ( ?) from the $2^{\text {nd }}$ to the $5^{\text {th }}$ toe). It is also important to remember that the femoral diaphysis unearthed in square F2 shows signs of gnawing by a carnivore such as the Brown Bear (Madelaine et al. 2008). Therefore, after decomposition of the body, the human deposit has been disturbed at least by the presence in the cave of these carnivores.

Except for the remains in G1 and E1, the coordinated bones are located in two areas representing distinct surfaces. A first zone, very limited, is localized in G3 with eight remains very close to each other. The second area corresponds to squares F3, F2, E2 and D2. The remains (at least 10 bones) appear to align on a north-east / south-west axis.

In $\mathrm{G} 3$, the distal extremity of the right tibia, the two talus, two right metatarsals and six foot phalanges (potentially three from the right foot and three from the left foot) were found. Between this area and the concentration of remains in G2, almost no human remains were coordinated. In the second area, except for two bones (a middle phalange of the right hand in F2 and a distal phalange of the first digit of the left hand in E2), all the coordinated remains relate to the right and left lower limbs.

All these observations suggest that in $\mathrm{G} 3$, the bones of the lower limbs extremity are in their original position. The repartition of the bones respects, indeed, again, the previously recognized anatomical logic of the body. The random distribution of the remains in the other squares would then be the result of post-depositional processes such as the presence in the cave of brown bears and/or the activities of the lagomorphs whose burrows have been noticed (see above). One of these appears to be also at the same level as the human remains (between the two structures considered as hearths). 
Figure 11 - Location of all the Regourdou 1 human remains that came to light both in 1957, and following the later excavations directed by E. Bonifay.

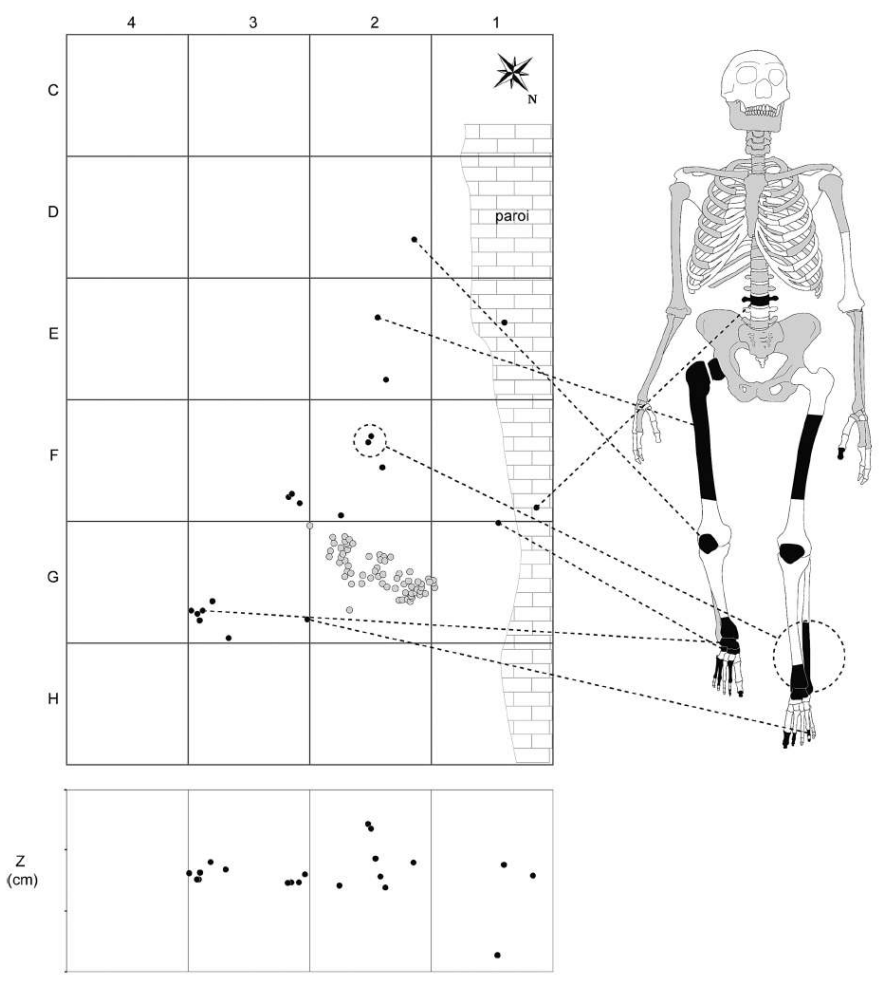

We have positioned the human remains found in 1957 in the southern part of square G2. Neandertal skeleton drawn by C. Beauval. Gray points : pieces found in 1957 ; black points : pieces discovered beginning in 1961.

\section{3 - About the position of the body of Regourdou 1}

According to Bonifay et al. (2007 - p 9-10, also see Defleur 1993.) "although disturbed by the Constant trench and the urgent rescue excavation of 1957, the position of the body can be reconstructed: it was folded in foetal position, knees drawn up under the chin, arms folded and hands close to the face. The head was turned toward the northeast. In line with the body, at the location of the legs (if they had remained laid out) were two brown bear tibias. As early as 1957, we noted the absence of the skull that was probably removed in the night of September 22, 1957 before Roger Constant came back on the excavation site (existence of cervical vertebrae in anatomical connection, including the atlas and axis). On the opposite, some long bones, which must have been found first during the digging of the Constant trench (femurs, tibias, fibula) were probably taken out of the burial at any time before the discovery announcement."

Despite a relatively poor state of conservation due to many fresh fractures, we now know that the long bones of the lower limbs are present. Therefore, they have not been removed, not during the works for digging the underground gallery by R. Constant nor by the people he invited into his site. It is the same with the atlas discovered on February 13, 2012 among the uncoordinated bone splinters, which therefore has never been observed in anatomical connection. If many bones appear in a chaotic position, some of them bring us information about the body position. In G2, the overall anatomical organization of the upper part of a body being respected, the position of the mandible (if we assume it relatively close to the one it had after the decomposition of 
the flesh) would plead for a head bent toward the trunk. The preserved anatomical connection between two metacarpals (fig. 8) side by side, seen by their palmar face and with their base still fixed in the section, suggests the presence of a hand in front of and close to the trunk. The position of the large long bones of the right upper limb does not indicate that it was folded since the humerus is between the mandible and the bones of the forearm. In the case where the arm would have been folded toward the top of the body, the opposite would have been observed with the bones of the forearm in front of the one of the arm. The position of the left arm is unknown. We assume that its three main long bones were probably removed during R. Constant's work (the left ulna is marked Reg 4 but see above, the left radius is marked. Sépul. 3, three other bone fragments on the left are without number and only one remain, the distal extremity of left ulna, is marked Reg No.51). Finally, considering the two areas (G2 and G3) that yielded the vast majority of the human remains, the body had the head to the west, the pelvic girdle at the limit of squares G2 and G3 and the feet at the boundary between G3 and $\mathrm{G} 4$ to the east (therefore almost $2 \mathrm{~m}$ from the head). Therefore, depending on the progress of our research, the simplest assumption about the position of the body, would be that of an individual laying down, perhaps, and with great caution, in left lateral decubitus.

The only part of the Regourdou 1 body still missing is the skull. Despite a very thorough review of all the faunal collection, no cranial fragment can be associated with it. Neither is there any isolated tooth of the upper jaw. According to our understanding of the circumstances of the discovery in September 1957, of the topography of the tunnel dug by R. Constant, of the taphonomic damages to the bones, we do not believe that the skull has been removed during the night of the discovery because this would imply it was in an exceptional state of conservation or that all the fragments were collected without missing one. Several assumptions, some of which can be combined, can simply explain this absence :

1. it has completely disappeared following runoff processes because it could have been located near the western wall of the cave. But teeth do preserve well and it is surprising not to have any ;

2. it was destroyed during the digging of the gallery before September 1957. F. Bordes himself points out that during the rescue excavation, some bones, very poorly preserved, could not be removed. It is therefore possible that what remained a much eroded skull was not identified by amateurs digging rapidly (and violently) stopping only on the material they recognized. Based on our assumption about the position of body of Regourdou 1, its skull could very well have been in an area dug before September 1957;

3. it was recovered by the Mousterian people like in Kebara 2 in Israel (Arensburg et al. 1985) ;

4. It is still within the filling of the cave having been moved by fauna.

For the last two hypotheses, only new excavations taking into account recent research developments and the continuation of our study of the remains unearthed between 1961 and 1964 will allow moving forward and discussing the role of Man in the setting up of the remains accumulated in the layer 4 defined by Bonifay (1964) that appears to be the one in which the human impact is the most important. Then we will possibly be able to discuss the existence of a Mousterian burial in Regourdou. 


\section{Conclusions} restituting the position of the Regourdou 1 body but also strong limitations (difficulty recognizing remains on photography, uncertainty about the position of the body, its location). If it were needed, it demonstrates the importance of acquiring a maximum of detailed information from the field. Indeed these make it possible to re-assess old discoveries according to current issues. Finally, we hope that the digital site model and the tools of photogrammetry will help us solve some persistent difficulties and propose a virtual reconstruction of the organization of some bones replaced in the site.

Considering and cross-referencing different information, much varied in quality (field minutes, drawings, graphic materials, information marked on or associated with the human bones, coordinates of the objects unearthed during the scheduled excavations in 1961), it was possible to position on the same plan (itself replaced in the grid established for the scheduled excavations from 1961 to 1964) very numerous bones of Regourdou 1 (160 remains currently known, let's recall that a right calcaneus unearthed between 1961 and 1964 represents a second individual). We note that they are overwhelmingly included in squares G2 and G3 and they are distributed in accordance with the anatomical logic of a human body lying head to the west, near the wall of the cave, and feet to the east.

Furthermore, the distribution of all the human remains on nearly $4 \mathrm{~m}^{2}$ and the space without human remains between squares G2 and G3 would be explained by postdepositional disturbance probably linked to the use of the cave by brown bears and/or wild rabbits that have set up their burrows in the sedimentary filling. The bones of the lower limbs would have been disturbed by these visits.

many causes that we are not yet able to discuss. The quality of some information available is certainly one of them. But it is not unusual that, for a Mousterian deposit (see for example the Dederiyeh 1 burial ; Akazawa et al. 2002), the taphonomic history is more complex than for more recent chronological periods, which creates potentially greater disturbances in the spatial distribution of the bone remains. In addition to the impacts associated with the use of the cave by various animals, erosion processes such as runoff could also have affected the bones since the top of the rising left side of the mandible and the proximal third of the left fibula are missing.

Finally, this approach exploring various unpublished field data has shown its interest in a vitul reconstrion of the res ization of some bones replaced in the site.

\section{BIBLIOGRAPHY}

\section{References}

AKAZAWA T., MUHESEN S., KONDO O., DODO Y., YONEDA M., GRIGGO Ch., ISHIDA H. 2002 Neanderthal burials of the Dederiyeh Cave. In : Akazawa T. et Muhesen S. (Ed.), Neanderthal 
burials. Excavations of the Dederiyeh Cave Afrin, Syria. Kyoto : International Research Center for Japanese Studies, p. 75-90.

ARENSBURG B., BAR-YOSEF O., CHECH M., GOLDBERG P., LAVILLE H., MEIGNEN L., RAK Y., TCHERNOV E., TILLIER A.-M., VANDERMEERSCH B. 1985 - Une sépulture néandertalienne dans la grotte de Kebara (Israël). Comptes rendus des séances de l'Académie des sciences de Paris, 300 (II), p. 227-230.

BINANT P. 1991 - Les sépultures du Paléolithique. Archéologie d'aujourd'hui. Paris : éditions Errance, $108 \mathrm{p}$.

BONIFAY E. 1961 inédit - Grotte du Regourdou, Montignac-sur-Vézère (Dordogne). Rapport sur les travaux effectués en 1961. Document dactylographié, p. 9

BONIFAY E. 1964 - La grotte de Régourdou (Montignac, Dordogne). Stratigraphie et industrie lithique moustérienne. L'Anthropologie, 68, p. 49-64.

BONIFAY E. 1965 - Un ensemble rituel moustérien à la grotte du Régourdou (Montignac, Dordogne). In : Actes du VIème Congrès International des Sciences Préhistoriques et Protohistoriques, Session I-IV. Rome, p. 136-140.

BONIFAY E., VANDERMEERSCH B. 1962 - Dépôts rituels d'ossements d'ours dans le gisement moustérien du Régourdou (Montignac, Dordogne). Comptes Rendus de l'Académie des Sciences de Paris, 255, p. 1635-1636.

BONIFAY E., VANDERMEERSCH B., COUTURE C. et PANATTONI R. 2007 - La sépulture néandertalienne du Régourdou (Montignac-sur-Vezère, Dordogne). Mercuès : Documents du Centre d'Etude et de Recherche sur les Lacs, Anciens lacs et Tourbières du Massif-Central, 18 p.

BONIFAY M.-F. 1989 - Analyse taphonomique des Ursidés de la grotte sépulcrale néanderthalienne du Régourdou (Dordogne, France). In : Otte M. (Ed.), L'homme de Néanderthal. Colloque international de Liège (4-7 décembre 1986). Eraul, 6, p. 45-47.

BONIFAY M.-F. 2008 - Importance de la population d'Ours bruns du Régourdou. Bulletin de la Société d'études et de recherches préhistoriques des Eyzies, 57, p. 14-24.

CAVANHIÉ N. 2009-2010 - L'ours qui a vu l'Homme ? Etude archéozoologique et taphonomique du site paléolithique moyen de Regourdou (Montignac, Dordogne, France). Paleo, 21, p. 39-64.

DONARD E. 1982 - Recherches sur les Léporinés quaternaires (Pléistocène moyen et supérieur, Holocène) Talence : Université Bordeaux 1, 1982. 191 p. Thèse de doctorat.

DEFLEUR A. 1993 - Les sépultures moustériennes. Paris : CNRS éditions, pp. 97-102.

DELAGES F. 1939 - La grotte de la Balutie. Mélanges Bégouëns, Toulouse, p. 161-169.

DELPECH F. 1996 - L'environnement animal des moustériens Quina du Périgord. Paleo, 8, p 31-46.

GÓMEZ-OLIVENCIA A., COUTURE-VESCHAMBRE C., MADELAINE S., MAUREILLE B. 2013 - The vertebral column of the Regourdou 1 Neandertal . Journal of Human Evolution 64, p. 582-607.

LAPLACE-JAURETCHE G. et MEROC L. 1954 - Application des coordonnées cartésiennes à la fouille d'un gisement. Bulletin de la Société préhistorique de France, 51, p. 58-66.

MADELAINE S., MAUREILLE B., CAVANHIÉ N., COUTURE-VESCHAMBRE C., BONIFAY E., ARMAND D., BONIFAY M.-F., DUDAY H., FOSSE P. et VANDERMEERSCH B. 2008 - Nouveaux restes humains moustériens rapportés au squelette néandertalien de Regourdou 1 (Regourdou, commune de Montignac, Dordogne, France). Paleo, 20, p. 101-114. 
MAUREILLE B. et VANDERMEERSCH B. 2007 - Les sépultures néandertaliennes. In :

VANDERMEERSCH B. et MAUREILLE B., 2007 (éds), Les Néandertaliens, biologie et cultures.

Documents préhistoriques 23, Paris : C.T.H.S, pp. 311-322.

MAUREILLE B., GÓMEZ-OLIVENCIA A., COUTURE-VESCHAMBRE C., MADELAINE S., HOLLIDAY T. sous presse - Nouveaux restes humains provenant du gisement de Regourdou (Montignac-surVézère, Dordogne, France). Paleo 26, 2015.

MAY F. 1986 - Les sépultures préhistoriques. Paris : éditions du CNRS, 264 p.

PELLETIER M., ROYER A., HOLLIDAY T., MAUREILLE B. sous presse - Lièvre et lapin à Regourdou (Montignac-sur-Vézère, Dordogne) : Études paléontologique et taphonomique de deux accumulations osseuses d'origine naturelle. Paleo 26, 2015.

PETTITT P. 2011 - The Palaeolithic Origins of Human Burial. London : Routledge, 307 p.

PIVETEAU J. 1959 - Les restes humains de la grotte de Regourdou (Dordogne). Comptes Rendus de l'Académie des Sciences de Paris, sér. D, 248, p. 40-44.

REVERDIT M. 1879 - Stations et traces des temps préhistoriques dans le canton de Montignac-surVézère (Dordogne). Bulletin de la Société Historique et Archéologique du Périgord, 5, p. 384-419.

SIMARD R. 1968 - Étude paléontologique et paléoclimatique de la microfaune du Régourdou (Montignac, Dordogne, France). Naturaliste Canadien, 95, p. 1435-1457.

\section{APPENDIXES}

\section{New inventory of human remains reported from Regourdou 1 and additional information on their marking.}

\section{Anatomical part}

- skeletal element / side / complete (C), subcomplete (SC) or fragmentary (F) / marking on the piece

\section{Cranium}

- Mandible / - / SC / 31

\section{Rachis}

- First cervical vertebra / right half / F / -

- Second cervical vertebra / right neural arch, den and vertebral body/ F / two fragments marked : Sous 31 ; Reg. 1957 sep. 32 (Under 31 : Reg 1957 sep.32)

- Second cervical vertebra / left neural arch / F / Nº 2

- Third cervical vertebra / C / Reg. 1957 sep. 
- Fragments of $4^{\text {th }}$ cervical vertebra / F / 2 fragments marked : Reg. Sep. 1957 derrière. Md ; Reg (Reg. Sep. 1957 behind Md ; Reg)

- $4^{\text {th }}$ cervical vertebra / spinous process / F / 32

- Fragment of 5 th cervical vertebra / - / F / -

- $5^{\text {th }}$ cervical vertebra / spinous process / F / Reg 8

- Fragment of $6^{\text {th }}$ cervical vertebra / - / C / Reg 195735

- Neural arch of $6^{\text {th }}$ cervical vertebra / - / F / Reg. $n^{\circ} 37$

- 7th cervical vertebra / - / C / Reg. Sous n 31

- 7th cervical vertebra / distal extremity of spinous process/ F / -

- $1^{\text {st }}$ thoracic vertebra / left neural arch / F / entre 51 et 47

- $1^{\text {st }}$ thoracic vertebra / left lamina - / F / Reg.

- $1^{\text {st }}$ thoracic vertebra / right lamina - / F / -

- $2^{\text {nd }}$ thoracic vertebra / - / C / Reg C ; Reg 1957 Sep. 39

- Thoracic vertebra (T3-T6, T8) / well preserved left superior articular facet and fragment of left inferior articular facet / F / Reg sous le $n^{\circ} 44$

- Thoracic vertebra (T3-T6, T8) / root of spinous process with right inferior articular facet / F / Regourdou Sep. $1957 \mathrm{n}^{\circ} 52$

- Body of $7^{\text {th }}$ thoracic vertebra / - / F / Reg D

- 7th thoracic vertebra / right superior articular facet, right transverse process and right pedicle / F / $\mathrm{n}^{\circ} 47-48,49$

- $7^{\text {th }}$ thoracic vertebra / pedicle and left articular facet / F / -

- $7^{\text {th }}$ thoracic vertebra / lamina and inferior articular facets / F / -

- Body of $8^{\text {th }}$ thoracic vertebra / - / F / Reg. 1957 sepult. 51

- Body of $9^{\text {th }}$ thoracic vertebra / - / F / Reg. 195751

- $9^{\text {th }}$ ( ?) thoracic vertebra / laminas, left inferior articular facet and spinous process / F / Reg. 1957 sep. 51

- $10^{\text {th }}$ thoracic vertebra / body and pedicles / F / Reg 1957

- $10^{\text {th }}$ thoracic vertebra / transverse process, lamina and left inferior articular facet and fragment of spinous process / F / Reg. Sep. 1957 derrière le bloc de la md

- $10^{\text {th }}$ thoracic vertebra / left superior articular facet / F / -

- $11^{\text {th }}$ thoracic vertebra / body, pedicles and superior articular surfaces / F / Reg sep 1957 sous le $n^{\circ} 46$

- $11^{\text {th }}$ thoracic vertebra / neural arch / F / -

- $12^{\text {th }}$ ( ?) thoracic vertebra / body / F / writing partially illegible : a8- 32a

- $12^{\text {th }}$ thoracic vertebra / neural arch / F / two fragments marked : Regourd Sep. 1957

$n^{\circ} 52 ; 58$ axe 32 poteau 
- Thoracic vertebra ( ?) / body / F / -

- Thoracic vertebra / left transverse process / F / -

- Thoracic vertebra / right transverse process / F / -

- Thoracic vertebra / left transverse process / F / Reg. $\mathrm{N}^{\circ} 51$

- Thoracic vertebra / superior articular process / F / 58 axe 32 poteau

- Thoracic or lumbar vertebra / body / F / Reg. $\mathrm{N}^{\circ} 47$

- $1^{\text {st }}$ lumbar vertebra / - / C / illegible writing

- Lumbar vertebra / transverse process / F /

- Lumbar vertebra (L2-L4) / body fragment and left pedicle / F / Reg. Sep 1957

- Lumbar vertebra (L2-L3) / neural arch / F / Reg 4B 192 /F1-3

- Lumbar vertebra (L2-L4) / body fragment and right pedicle / F / Regourdou n ${ }^{\circ} 50$

- Lumbar vertebra (L4-L5) / root of spinous process / F / Reg N51

- $5^{\text {th }}$ lumbar vertebra / fragment of body / F / Reg 195751

- $5^{\text {th }}$ lumbar vertebra / fragment of body / F / 51

- Lumbar vertebra / fragment of spinous process / F / $n^{\circ} 47,48,49$

- Sacrum / - / F / Nothing

- Coccyx / 1st segment / F / -

\section{Ribs}

- $1^{\text {st }}$ rib / D / SC / Regourdou sep. 1957 nº 32

- $1^{\text {st }} \mathrm{rib} / \mathrm{G} / \mathrm{SC} /$ Reg. 1957 sép.

$\cdot 2^{\text {nd }}$ rib, tubercle / D / F / -

- $2^{\text {nd }}$ rib, body / D ? / F / two fragments : unmarked ; R

- $2^{\text {nd }}$ rib, sternal extremity / D / F / -

- $2^{\text {nd }}$ rib, head, neck and tubercle / G / F / Regourdou Sep 1957

- $2^{\text {nd }}$ rib, body / G / F / Reg. 1957 sépult. 25

- $2^{\text {nd }}$ rib, body / G / F / two fragments : Regourdou. Sep. 1957 Sur le bloc ou était la p. droite de la md. ; pas marqué (on the block where the right p. of the md was ; unmarked)

- $3^{\text {rd }}$ rib, neck, tubercle, body / G / F / two fragments : n 47-48-49; Reg Sep. 195. n 18

- $4^{\text {th }}$ rib, tubercle, body / D / F / two fragments : n 47, 48, 49 ; Reg Sep 1957 nº 47, 48, 49

- $4^{\text {th }}$ rib, body / D / F / -

- $4^{\text {th }}$ rib, body and sternal extremity / D / F / -

- $4^{\text {th }}$ rib, tubercle, body / G / F / two fragments : Reg. 1957 Sep. p. md ; Reg. 1957 Sep. p.n.d 
- $6^{\text {th }}$ (?) rib, body/ ? / F / two fragments : under bone $47 ; \mathrm{n}^{\circ} 47,48,49$

- $7^{\text {th }}$ (?) rib, body / D / F / three fragments : unmarked ; Reg n $n^{\circ} 47 ; n^{\circ} 47,48,49$

- $8^{\text {th }}$ ( ?) rib, body and sternal extremity / D / F / two fragments : Reg. 1957 Sep. ; Reg.

1957 Sepult

- $9^{\text {th }}$ rib, head, neck and tubercle / D/ F / Reg. 1957 Sep. p. md.

- $9^{\text {th }}$ ( ?) rib, body / D / F / two fragments : Reg 1957 sep. nº 21 ; Reg. 1957 Sep

- $9^{\text {th }}$ ( ?) rib, body / G / F / Regourdou under femur

- gh $^{\text {th }}$ ?) rib, body / G / F / Reg. 1957 Sep. p. md.

- $11^{\text {th }}$ rib, body / D / C / three fragments : Reg 1957 sepult 51; Regourdou, sp. $1957 ; 58$ par \% axe, 32 du poteau ( 58 by \% axis, 32 from the post)

- $11^{\text {th }}$ rib, body / G / F / Reg. 1957 sepult. 51

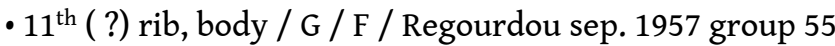

- $12^{\text {th }}$ rib, body / D / F / Regourdou sep 1957 nº 52

- Rib (4-8), head and neck / D / F / -

- Rib (4-8), head and neck / D / F / N 47-48-49

- Rib (3-8), body / G / F / Reg. Sep. 1957 derrière la md (behind the md)

- Rib, body ? / ? / F / 58 axis 32 post

- Rib (3-9), body / G / F / between $n^{\circ} 51$ and 47

- Rib (6-8), tubercle and body / G / F / -

\section{Sternum}

- Manubrium / - / C / 195749

- Body (S2 and S3) / - / C / -

- Body (S4 and S5) / - / F / 58 axis 32 post

\section{Shoulder girdle}

- Clavicle / G / SC / Reg. 1957 sépult. No. 41

- Clavicle / D / SC / Reg. 1957 sépult.

- Scapula (coracoid process) / G / C / -

\section{Upper limbs}

- Humerus, proximal half of the diaphysis / G / F / Le Regourdou

- Humerus, distal half / G / F / R G

- Humerus / D / C / Reg. Sep. 1957

- Ulna, diaphysis and basis of the head / G / SC / Reg. sep. 1957 Reg 4 
- Ulna / D / SC / Reg. 1957 sepult.

- Ulna, distal extremity / G / F / Reg. Nº 51

- Radius, proximal half / G / F / Reg. 1957 sepul. 3

- Radius, diaphysis fragment / G / F / Reg. 1957 sep. p. md.

- Radius / D / C / Reg. Sep. 1957 / regourdou ... ... No. 24

\section{Hands}

- Trapezoid D / C / -

- Trapezoid / G / C / Reg 3 ? (maybe 30)

- Scaphoid / D / C / Reg 1957 sepult. Reg 27 Reg 26

- Scaphoid / G / C / Reg 195751 Reg 29

- Hamate / D / C / Reg 57 sep.

- Hamate / G / C / Reg N 51

- Triquetral G / C / Reg 1957

- Lunate / G / C / -

- Capitate / G / F / R sous 31

- Pisiform / D ? / C / R D Reg 32

- Metacarpal I, distal three quarters / D / SC / -

- Metacarpal I / G / C / MC I R G

- Metacarpal II / D / C / Reg 1957 Sep 57 MC II

- Metacarpal II, base missing / G / SC / Reg Sep 1957 sur le bloc ou était la p. droite de la $\mathrm{Md}$ (on block on which the right p. of the Md was)

- Metacarpal III, base missing / D / SC / G Reg

- Metacarpal III / G / SC / Sep 1957 N³ 39 R D MC III

- Metacarpal III, proximal extremity / G / F / -

- Metacarpal IV, missing proximal extremity / D / SC / Reg 1957 sep 1 ter Reg. 14

- Metacarpal IV / G / SC / R M IV (writing ?)

- Metacarpal V / G / SC / G

- Proximal half of Metacarpal V ? / D / SC / Reg. Sep. 1957 sous le nº 44

- Proximal phalange R I / G ? / C / R

- Proximal phalange R II ? / G ? / C / R

- Proximal phalange R III ? / G ? / C / R G

- Proximal phalange R IV ? / G ? / C / R G

- Proximal phalange R V ? / G ? / C / Reg 1957 G Sep 35 Reg. 18 
- Proximal phalange R II ? / D ? / C / R D

- Proximal phalange R III ? / D ? / C / R D

- Proximal phalange R IV ? / D ? / C / R D

- Proximal phalange R V ? / D ? / C / D

- Middle phalange R II ? / G ? / C / F2-87 Reg

- Middle phalange R III ? / G ? / C / R D

- Middle phalange R IV ? / G ? / C / R G

- Middle phalange R V ? / G ? / C / -

- Middle phalange R III ? / D ? / C / R

- Middle phalange R IV ? / D ? / C / R

- Middle phalange R V ? / D ? / C / Reg 1957 sep. D

- Distal phalange R I / G ? / C / R E2 131

- Distal phalange R II ? / G ? / C / R G

- Distal phalange R III ? / D ? / C / illegible

- Distal phalange R IV ? / D ? / C / D

- Distal phalange R V ? / D ? / C / 1957

- Distal phalange R ? / G ? / C / 1957 G

- Distal phalange R ? / G ? / C / G Reg 1957

- Distal phalange R ? / G ? / C / -

\section{Pelvic girdle}

- Coxal, part of the wing of ilium with large ischial notch / D / F / Regourdou under femur and Regourdou 1957

- Coxal, fragment of acetabulum cavity and tuberosity of the ischium / D / F / D ; Reg 1957 sépult. $\mathrm{N}^{\circ} 47$ Reg 23

- Coxal, pubis fragment / D / F / Reg. 1957 sepult.

- Coxal, part of the wing of ilium with large ischial notch/ G / F / -

- Coxal, fragment of acetabulum cavity / G / F / -

- Coxal, fragment of tuberosity of the ischium / G / F / Reg sous le femur (Reg under the femur)

\section{Lower limbs}

- Femur, diaphysis / D / SC / Reg-4-265 ; F2 58

- Femur, head / D / SC / Reg 4B 4050; E2 69

- Femur, diaphysis / G / F / - 
- Patella / G / C / Regourdou F3 90

- Patella / D / C / Reg 4C 3848 ; D2 54

- Tibia, distal extremity / G / SC / Reg 4A 614 ; G2 14

- Tibia, distal extremity / D / F / G3 11

- Fibula, diaphysis / D / C / Reg 1957 sepult. Sous pierre n 1

- Fibula, distal half / G / C / Reg 4A 618 ; F2 18

- Fibula, distal extremity / D / SC / Reg. 1957 sep.

Feet

- Talus / D / C / Regourdou G3 63

- Talus / G / C / Regourdou G3 76

- Calcaneus / D / F / Reg 35 ou R = G1 35

- Calcaneus / G / - / -

- Navicular / D / C / Reg 4A 351 /F2 148

- Metatarsal R II / D / C / Regourdou G3 90 MT 3

- Metatarsal R IV / D / C / Regourdou G3 74 D MT4

- Metatarsal R V / D / C / Regourdou Reg F3-92 D MT5

- Proximal phalange R I / G / C / Regourdou G3 88

- Proximal phalange R II à V ? / D ? / C / R E1 26

- Proximal phalange R II à V ? / G ? / SC / R G G3 89

- Proximal phalange R II à V ? / G ? / C / R G (G ? ?)

- Middle phalange R II, R III / D ? / C / R D G3 82

- Middle phalange R II ou R III / G ? / C / R G F3 91

- Middle phalange R IV ou R V / G ? / C / R G G3 82

- Middle phalange / D ? / C / F2-87 Reg

- Distal phalange RI / D / C / R F3 92 D

- Distal phalange Phalange R I / G / C / R G G3 88

- Distal phalange Phalange R II R III / D ? / C / G3 88

- Distal phalange Phalange R II ou RIII ? / G ? / C / R G 34

- Distal phalange Phalange R IV ou R V / G ? / C / R G G3 88

\section{ABSTRACTS}

Aside from the work of Bonifay (see Bonifay et al. 2007 for one of the more recent papers) and various articles following these earlier works (e.g., Binant 1991, Defleur 1993, Maureille et 
Vandermeersch 2007, Pettitt 2011, see also May 1986 for a more critical analysis), the in situ position of the remains of Regourdou 1 from layer 4 has never actually been discussed on the basis of available data from the salvage operation carried out in October 1957 by E. Bonifay and G. Laplace-Jauretche, under the administrative authority of François Bordes, or from the subsequent, more systematic, excavations directed by E. Bonifay between 1961 and 1964 .

Via the compilation of available information from a number of unpublished documents (François Bordes' field notes, drawings made during the salvage operation, photographs taken in 1957, 1961 and 1962, as well as databases from the 1961 to 1964 excavations), and also a new inventory of human remains (both previously known and recently discovered), it is now possible to more accurately reconstruct the position of the human remains in a Cartesian system. In this, we assume that the concentration of remains uncovered during the salvage operation was in square G2, according to the preliminary systematic excavations carried out in 1961 . They also bring to light that while practically no anatomical connections can be demonstrated with any certainty and despite significant disruptions (all of the hominin remains are spread over 9 squares : G1 to G3, F1 to F3, E1 and E2, D2) - they are mainly positioned in squares G2 and G3 to some degree with respect to the anatomical logic of the human body. We therefore assume that Regourdou 1 was lying flat, with its head to the west - perhaps upon its trunk - close to the wall of the cavity. This result is different from the fetal position hypothesis proposed in Bonifay et al. (2007). Moreover many post-depositional (albeit Pleistocene) disturbances are also evident. We believe that they were likely the result of the utilization and modification of the cavity by brown bears and lagomorphs.

Only new excavations at the site, and a better taphonomic understanding of Bonifay's (1964) layer 4 (in which Regourdou 1 was found), and the exact role of humans in its formation, i.e., their anthropic impact on the layer, will allow us to discuss in more detail the nature of the deposition of the body, and, hopefully, the absence of the skull.

\section{INDEX}

Keywords: Neanderthal, Taphonomy, Excavation, Burial, François Bordes

\section{AUTHORS}

\section{BRUNO MAUREILLE}

Université de Bordeaux, CNRS, Ministère de la Culture et de la Communication, ; PACEA

UMR5199, FR-33615 Pessac - b.maureille@pacea.u-bordeaux1.fr

\section{TRENTON HOLLIDAY}

Department of Anthropology, 101 Dinwiddie Hall, Tulane University, New Orleans, Louisiana 70118 USA ; Evolutionary Studies Institute, University of the Witwatersrand, Private Bag 3, Wits 2050, Republic of South Africa - thollid@tulane.edu

\section{AURÉLIEN ROYER}

Université de Bourgogne, Biogéosciences, UMR CNRS 6282, 6 Boulevard Gabriel, FR-21000 Dijon ; École Pratique des Hautes Études, Laboratoire EPHE PALEVO, FR-21000 Dijon aurelien_royer@hotmail.com 


\section{MAXIME PELLETIER}

Aix Marseille Université, CNRS, Ministère de la Culture et de la Communication, LAMPEA UMR7269, FR-13094 Aix-en-Provence - maxime.pelletier@etu.univ-amu.fr

\section{STÉPHANE MADELAINE}

Musée national de Préhistoire, 1 rue du Musée, FR-24620 Les Eyzies-de-Tayac -

stephane.madelaine@culture.gouv.fr ;

Université de Bordeaux, CNRS, Ministère de la Culture et de la Communication, ; PACEA

UMR5199, FR-33615 Pessac

\section{FRANÇOIS LACRAMPE-CUYAUBÈRE}

SARL Archéosphère - FR-33000 Bordeaux - f.lacrampe@archeosphere.com

Get In Situ - CH-Lausanne - x.muth@getinsitu.com ; f.lacrampe@getinsitu.com

\section{XAVIER MUTH}

Get In Situ - CH-Lausanne - x.muth@getinsitu.com ; f.lacrampe@getinsitu.com

\section{ERWAN LE GUEUT}

La Matz, FR-22490 Plouer-sur-Rance - lgerwan@hotmail.fr

\section{CHRISTINE COUTURE-VESCHAMBRE}

Université de Bordeaux, CNRS, Ministère de la Culture et de la Communication, ; PACEA UMR5199, FR-33615 Pessac - c.couture@pacea.u-bordeaux1.fr

\section{ASIER GÓMEZ-OLIVENCIA}

Dept. Estratigrafía y Paleontología, Facultad de Ciencia y Tecnología, Euskal Herriko Unibertsitatea, UPV-EHU. Apdo. 644, ES-48080 Bilbao ; IKERBASQUE. Basque Foundation for Science ; Équipe de Paléontologie Humaine, UMR 7194, CNRS, Département de Préhistoire, Muséum national d'Histoire naturelle. Musée de l'Homme, 17, Place du Trocadéro, FR-75016 Paris ; Centro UCM-ISCIII de Investigación sobre Evolución y Comportamiento Humanos, Avda. Monforte de Lemos 5 (Pabellón 14), ES-28029 Madrid - asier.gomezo@ehu.eus

\section{EMMANUEL DISCAMPS}

AHKR Institute, University of Bergen, Øysteinsgate 1, PO Box 7805, N-5020 Bergen, Norway ediscamps@gmail.com

Université de Bordeaux, CNRS, Ministère de la Culture et de la Communication, ; PACEA UMR5199, FR-33615 Pessac

\section{JEAN-PIERRE TEXIER}

Université de Bordeaux, CNRS, Ministère de la Culture et de la Communication, ; PACEA UMR5199, FR-33615 Pessac-j-pierre.texier@wanadoo.fr

\section{ALAIN TURQ}

Musée national de Préhistoire, 1 rue du Musée, FR-24620 Les Eyzies-de-Tayac alain.turq@culture.gouv.fr Université de Bordeaux, CNRS, Ministère de la Culture et de la Communication, ; PACEA UMR5199, FR-33615 Pessac 


\section{CHRISTELLE LAHAYE}

Université Bordeaux Montaigne, CNRS, IRAMAT-CRP2A UMR5060, FR-33607 Pessac christelle.lahaye@u-bordeaux-montaigne.fr 